\title{
Massification of the Higher Education as a Way to Individual Subjective Wellbeing
}

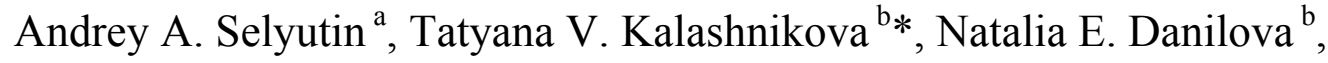 \\ Natalia V. Frolova ${ }^{\mathrm{c}}$ \\ * Corresponding author: Kalashnikova Tatyana, tvkalash@tpu.ru
}

\begin{abstract}
${ }^{a}$ Chelyabinsk State University, Bratiev Kashirinykh str., 129, Chelyabinsk, Russia, blind11@ya.ru, +79642410302
${ }^{b}$ National Research Tomsk Polytechnic University, Lenin Avenue, 30,Tomsk, Russia, tvkalash@tpu.ru, +79039515173 ${ }^{c}$ Nizhnevartovsk Institute of Economics \& Law branch of Tyumen state university, Druzhbi Narodov str., 13a, Nizhnevartovsk, Russia,nat68366847@yandex.ru,+79129383476
\end{abstract}

\begin{abstract}
http://dx.doi.org/10.15405/epsbs.2017.01.35

The massification of the university education is inevitable process nowadays. On the one hand it allows solving the problem of knowledge generation and dissemination. On the other hand it helps individuals to achieve the subjective wellbeing, which is based on acquisition of knowledge that is necessary for the professional and individual orientation. In this article authors made an attempt to set tendency between individual's participation in the educational process and the acquisition of wellbeing's state. Taking into account modern trend of continuous education, authors as well suppose the existence of permanent wellbeing state. This statement is partially proven by social surveys and research's data, which has been conducted in Russia, Brazil, South Africa and other countries. Attractiveness and accessibility of education for people from different social groups determine the future level of public education. The rapid technological development of society, accessibility and mass character of educational programs, unconscious strivings of the major part of society to wellbeing must inevitably lead to the growth of average citizen's accomplishment.
\end{abstract}

(C) 2017 Published by Future Academy www.FutureAcademy.org.uk

Keywords: Massification of the higher education, wellbeing, knowledge society.

\section{Introduction}

The processes of globalization and formation of the information society have led to radical changes of the importance of higher education for socio-economical development. It became one of the core elements of social infrastructure of developed countries. Nowadays, knowledge is more valuable resource than tangible assets and the role of the higher education institutions cannot be overestimated 
from that perspective. Universities are the main resource of knowledge generation and dissemination. The transformation of the higher education system in many countries from exclusive education to mass-scale one can be considered as a respond to the new socio-economical development demands. The first country that introduced this transformation was USA in the late 1920's. European countries implemented this practice in 1960's followed by developing Asian countries in 1970's-1980's (Belotserkovsky, 2011).

The number of students is counted to 150 million now throughout the world, which is twice as many compare to the same number a couple decades ago. The number is expected to grow by another 100 million students by 2020. Essentially, there are two countries that are supposed to be responsible for this growth - India and China. Access simplification to the higher education is necessary not only due to the growth of a skilled labor demand, but also because it helps people discover new opportunities for social mobility and find more interesting jobs (Altbach, 2015). The proportion of adults who have higher education in developed countries has increased from $22 \%$ in 1975 to $40 \%$ in 2000. The phenomenon of "massification" is already distributed worldwide. The number of students has doubled in China and India in the 90's and it has almost tripled in Russia in the past 15 years. However, according to the results of census in 2002, the share of Russian people who have higher education is still extremely low and amount to only $18 \%$. Taking into account the needs of the new technological waves we are likely to switch to mass higher education at least at the first level Bachelor degree, just as at the beginning of the XX century when industrialization required secondarylevel education. One of the consequences of this trend is the need to enroll those who recently considered being 'incapable' to get traditional higher education and pass entrance examinations. In order to cope with this trend it is necessary to adjust teaching methods and techniques to implement wider range of styles and speed of education. country.

\section{The goal}

Education is a conscious process of knowledge acquisition and skills development for the purpose of its implementation in appropriate situations. Accumulation and use of knowledge are the main goals of education, based on the principles of the economic model of modern society - knowledge society. Education is the conscious and organized learning process what implies that any discussion on this subject cannot be limited to the process of knowledge acquisition and verification. We should consider not only the way knowledge is acquired and verified, but also whether the access to them is controlled and, therefore, can be made more liberal (Report UNESCO, 2015).

From this perspective, the massive knowledge transfer (so called massification of knowledge) provides access to everyone, thereby forming a positive attitude towards the acquisition of knowledge, as well as a positive model of their use and transfer. This is considered to have very positive influence on the level of personal wellbeing.

\section{Massification of higher education as need}

Over the last quarter of the XX century, the Russian higher education institutions have gone through the process of transformation from the G2G (Government-to-Government) providers of elite 
http://dx.doi.org/10.15405/epsbs.2017.01.35

eISSN: 2357-1330 / Corresponding Author: Kalashnikova Tatyana

Selection and peer-review under responsibility of the Organizing Committee of the conference

personnel to the direction of B2B (Business-to-Business) providers of skilled and competent personnel. Higher education has transformed from the demand of the government sector into demand of the business sector - people and companies. It was basically simplified at least at the level - Bachelor degree. This is a new market segment, with slightly different interests, needs and motivations. 'Massification' of the higher education is actually a process of adaptation to needs of mass, average student at the bachelor degree level.

Table 1. Ansoff matrix (university strategic model change) (Ansoff, 2009)

\begin{tabular}{cccc}
\hline & & PRODUCT & Bachelor \\
\hline & Government order & New specialities & Bachelor program development with accordance \\
of Bologna system
\end{tabular}

'Massification' of the higher education is actually a process of adaptation to needs of mass, average student at the bachelor degree level. In the longer term, the segment of paying students and the growing share of practice-oriented students will transform universities to incubators or consulting centers for business development. In this case graduating students are going to get not only a diploma after defense but also a job created by themselves while education process (Alyoshina, 2014).

Mass higher education is a factor which transforms a common motivational background of applicants when the access to the higher education is open not only to the elite segments of the population, but also to the representatives of other social groups that previously did not have such possibility (Kurennoy, 2011). Nowadays, there are more students at universities whose parents do not have a higher education. New distance learning techniques make education possible even for the people who live in remote regions of the world (Report UNICEF, 2000).

The attractiveness of education for young people, their motivation, accessibility of the education for people from different social groups, all of these factors essentially determine the future level of education of population, the number of skilled workers and the quality of their education. This plays a crucial role in terms of the modern world trends. The problem is also directly connected with so called social wellbeing of the population. Education establishes a framework for distinction between further ways of life of "strong" and "weak" groups. The correspondence between expectations, which young people have on the threshold of adulthood and the reality of their actual achievements defines the individuals' place in life. There are other factors that also influence this place such as the society and circumstances of time and place. Perception of the impossibility to achieve the desired status or the planned standard of living, impossibility to do favorite job will inevitably cause permanent dissatisfaction of individuals with their position. Young people become convinced that their interests are infringed; they are socially and economically unfulfilled (Konstantinovsky, 2010). 


\section{Life-long learning as a mean of life-long wellbeing}

Modern science does not have a generally accepted definition of the term "wellbeing". Despite the wide use of the term in scientific and popular-scientific literature the term is still not clearly defined. Aristotle in his "Ethics" observes that generally people agree with regard to the term - wellbeing, but have different understanding of its meaning. If we generalize ideas about welfare in its various renderings (psychological, philosophical, social, etc.), we can deduce the following definition: individual wellbeing is an integral characteristic of the human life quality in society which is reflected in the positive social status achievement and includes such factors as: the general state of health, availability of work, overall working environment, education, existence of friends and family, hobbies and leisure activities.

The All-Russia Public Opinion Research Center published the result of population survey on the topic of individual happiness conducted annually since 2008. Sociologists have asked people whether they consider themselves to be happy, and explored the reasons for affirmative and negative answers. And who, in their opinion surround them more - happy or unhappy people. The survey found that people's happiness depends primarily on personal factors, rather than on the surrounding reality. Those who feel happy associate this feeling, first of all, with the welfare of the family (29\%). Parental status or existence of grandchildren turned out to be also a very important factor of happiness (18\%) and of happy life in the whole (17\%). Among other reasons for happiness were good job (10\%), state of the own health and health of the loved ones $(6 \%)$, absence of concerns $(3 \%)$.

According to Russian scientists, it is the way we interpret the circumstances of the personal life that affects our happiness. Most of those who are engaged in research in this area (including genetics), generally agree that life circumstances have an impact on happiness. Our feelings, thoughts, behavior and actions to a greater extent depend on our upbringing, social and cultural factors. Hence, happiness and unhappiness can be considered as acquired skills (Leontyeva et al., 2015).

Education seems to be one of the main processes in society, contributing to the socialization of the individual. The concept of the lifelong learning is the culmination of a model of individual educational path planning which is in fact means never ending educational process and as a result life term wellbeing. The data obtained by scientists during the realization of an international project called "Education, wellbeing and developing economies of Russia, Brazil and South Africa" can prove this hypothesis (Daniels et al., 2010). Thus, a number of researches noticed the correlation between levels of education and life satisfaction. Some studies indicate that the highest level of life satisfaction have people with a median level of education. The impact of education on subjective wellbeing is observable at the group and individual levels.

Three aspects of impact of the education on economic wellbeing were also identified by comparison of statistical data of the participated in research countries:

- Direct impact: education contributes to the development of resources and inclinations that are useful in the long run.

- Indirect impact: education is a source of vitality and protects against some risk factors.

- Cumulative effect: education systems activity changes the whole socioeconomic environment (Daniels et al., 2010). 


\section{Conclusion}

Thus, the solution to many problems connected with the achievement of individual wellbeing, can be the enhancement of the education system efficiency. Essentially, education is the ability to produce more good products at a lower consumption of resources. And this task, according to the historical experience, has always been solved by introducing new technologies. The first technological revolution, which started the process of the higher education massification, is believed to be the invention of the printing machine by Johannes Gutenberg. In fact, this innovation has caused hot debates at that moment whether the books that are so easily copied could eventually completely replace teachers and make this profession useless.

As we know, it still has not happened yet, even almost 600 years later. Every technological revolution that has an educational perspective causes similar concerns in the academic environment. The same happened when television educational programs or full distance learning courses were created. Most recent example is the creation and rapid spread of the remote computer learning technologies. Experience shows that new technologies do not replace the traditional higher education institutions, but on the contrary, make them stronger and more competitive especially those of them who have successfully mastered the technology.

That is educational technologies that can help to cope with the issue of massification, facilitating the creation of multiple individual educational paths for a wide range of students, including those who have different levels of education, styles and pace of learning. They can help in solving other problems. One of the important steps towards the formalization of the education quality appeared to be the competence approach, stated in the governmental educational standards of new generation. The essence of the approach comprises three parts: 1) Joint work with the potential employers on the creation of set of required competences which graduates must have to succeed in the field; 2) The creation of procedures and tools for the evaluation of achievement of the desired competencies; 3 ) The creation of an educational program leading to the development of these competencies.

Competence approach involves the active use of new educational technologies as the results of mastering the education programs depends on content of subject and organization of educational process. Competence approach, if properly applied, gives priority to a student, his employability and full professional and personal realization (that is actually a working mechanism of achieving individual wellbeing). The main mechanism for the implementation of these goals is to establish close, long-term and stable relations of the university with real life economy and business.

\section{References}

Altbach, P. (2015). Massification of the higher education and global knowledge economy: continuing contradictions. International higher education, 80, 9.

Alyoshina, I. (2014). Mass higher education: new customer value, marketing, strategy. Country capital. Retrieved from http://kapital-rus.ru/articles/article/268344/

Ansoff, H. I. (2009). Strategic Management: Classic Edition. Piter.

Belotserkovsky, A. (2011). About "quality" and "quantity" of education. Higher education in Russia, 4, 3-10.

Daniels, G., Lauder, H., Lessa, A., Margolis, A., Rubtsov, V., \& Shvedovskii, A. (2010) International project "Education, wellbeing and developing economies of Russia, Brazil and South Africa" Retrieved from http://psyjournals.ru/edu_economy_wellbeing/issue/36289.shtml 
eISSN: $2357-1330$

Selection \& Peer-review under responsibility of the Conference Organization Committee

Konstantinovsky, D. (2010). Inequality in education: Russian situation. Monitoring of public opinion, 5.

Kurennoy, V. (2011). Bastard of modern. About the current university crisis. New Literature Review, 3.

Leontyeva, E., Kalashnikova, T., Danilova, N. \& Krakovetckaya, I. (2015). Subjective well-being as a result of the realization of projects of the elderly's involvement into the social life. II International Scientific Symposium on Lifelong wellbeing in the World WELLSO 2015. The European Proceedings of Social and Behavioural Sciences, Volume VII, 1-6. doi.org/10.15405/epsbs(2357-1330).2016.2

Rethinking the education: education as a public good. (2015). UNESCO, 86. Retrieved from http://unesdoc.unesco.org/images/0023/002325/232555r.pdf

Youth in a Changing Society. (2000). UNICEF Report № 7. Florence, 53. 